\title{
Research on the Theory and Practice of Improving the Scientific Research Innovation Ability in Independent College
}

\author{
Ye Shitong \\ Huali College Guangdong University of Technology \\ Guangzhou, China \\ yesigeng@163.com
}

\author{
Ke Jianbo \\ Huali College Guangdong University of Technology \\ Guangzhou, China
}

\author{
Huang Linwei \\ Huali College Guangdong University of Technology \\ Guangzhou, China
}

\begin{abstract}
The ability of scientific research innovation plays an important role in the development of independent colleges. This article starts from the concept of scientific research innovation; know that scientific research and innovation is different from the previous thinking and behavior in a series of scientific research activities, such as project, demonstration, research method, data processing, phenomenon analysis, equipment combination, project understanding and abstraction and so on. Independent college should adopt a positive attitude and take effective measures to strengthen the training of teachers' scientific research ability, to combine teaching with scientific research, and to form a good interaction, cultivate modern talents with innovative awareness, innovative ability that meet the requirements of the development of the times.
\end{abstract}

Keywords-Independent college; scientific research innovation; scientific research activities; research method

\section{INTRODUCTION}

Independent college is a new mechanisms and new models of higher education, is an important part of China's ordinary undergraduate education. It is mentioned in the "National Medium-Long-Term Educational Reform and Development Plan (2010-2020)"'[1] and "National Long-Term Talent Development Plan (2010-2020)"'[2] that reform and innovation is a powerful driving force for the development of education, but also one of the working principles. We should focus on the reform of the institutional mechanisms, encourage local and schools to carry out bold exploration and experimentation, and accelerate the pace of reform in important areas and key links. General Secretary $\mathrm{Hu}$ Jintao speech at the celebration of the 100 anniversary of Tsinghua University's conference[3], pointed out that the overall improvement of the quality of higher education; we must vigorously serve the economic and social development, closely focus on the theme of scientific development, accelerate the transformation of the main line of economic development, and continuously enhance the capacity of serving the economic and social development. Therefore,

Education research project of Guangdong Education Research Institute, 2014 (GDJY-2014-C-b033). proposed to enhance the level of scientific research, give full play to the important role of colleges and universities in the national innovation system, and encourage universities to contribute to knowledge innovation, technological innovation and regional innovation.

The characteristics of scientific research innovation can be seen as a student or teacher on the basis of being familiar with the previous knowledge that further abstracted or converted, when they doing research activities.

\section{Current Situation of Scientific Research in INDEPENDENT COLLEGE}

With the rapid development of science and technology and social economy, the development trend of higher education at home and abroad has two remarkable characteristics. Firstly, the social service function of higher education has been strengthened, and has become an important force to promote social and economic development. Secondly, the structure of higher education is constantly adjusted, and the cultivation of applied talents has gradually become an important part of higher education[4].

In China, although the scientific research and innovation of independent colleges cannot compared with 211, 985 and other key undergraduate universities, doesn't mean that the independent college do not need to develop. At present, the development of independent college can be described as leaps and bounds. However, the level of scientific research in independent college is in a low level, and there is a big difference between universities. The proportion coefficient in universities of the input and result of scientific research is in a very unsatisfactory situation.

In foreign countries, colleges and universities have attached great importance to scientific research; the state is strongly support the scientific research of independent colleges, such as Harvard, MIT and so on. As far as possible to reduce the interference of the teachers engaged in scientific research, the research team is selected from the same field, 
different levels and different research direction, the entire team has the characteristics of high efficiency, stable, capable and so on.

Independent college is not only an important part of higher education, but the quality of personnel training also very important. After years of starting, independent colleges are in the transition stage and there are many problems. The key is to improve the education level; however, scientific research is an important way to improve the quality of personnel training, and innovation is the inevitable requirement of it[5]. It is undeniable that independent colleges compared with general public universities, their scientific research are still in the initial stage, and the problem is that independent colleges have less investment in research funding, scientific research echelon structure is irrational, the achievement quality is low, the quantity is little, and the atmosphere is weak and so on[6]. During the period of "Twelfth Five-Year Plan", we put forward that the independent colleges must adhere to the road of industry-university-institute cooperation, uses applied research to drive teaching and research, and then promote teaching. Under the new situation, independent colleges should use the vision of development, combined with its own characteristics, take a proactive approach to overcome the difficulties and take effective measures to train teachers' scientific research ability, to further promote the development of scientific research, promote the sustainable development of the college and enhance the core competitiveness.

\section{ReseARCH Methods to IMPRove the AbILITY of SCIENTIFIC RESEARCH AND INNOVATION IN INDEPENDENT College}

\section{A. Initial preparation stage}

1) Documentary Research Method: Based on the school's "Electronic Resource Databases", to collect information documents which are related to the scientific research innovation of independent colleges, organization of teachers, students for the practical experience exchange, and put forward the plan and decision of improving the ability of scientific research innovation in independent colleges.

2) Survey Research Method: According to the questions raised by the team of teachers and students and the programs and decisions to be implemented and the programs and decisions to be implemented. Briefly summarized as a singlechoice questions and essay questions, design into the questionnaire, and then extract a representative answer. Teachers and students for the survey fully understand their degree of approval of our proposed program and decisionmaking. And adjust the program appropriately in the light of the results so that the second phase can proceed.

\section{B. Medium-term practice stage}

1) Action Research Method: According to the problems and behaviors of students in the process of practical and textual research, timely revision of the program and put it into practice, and solve the problem before it arises.
2) Experiential Summary Method: After the implementation of the institutional mechanisms or programs, all the solutions and the results are summarized records each time. Constantly practice to gain experience, improve the institutional mechanism, and sublimated into theory.

\section{Post-effectiveness stage}

Statistical Analysis Method: Collating all the investigations and the results of the implementation, to analyze and summarize the reason in it, and to carry out reform and innovation.

\section{MEASuRES to IMPRove THE AbILITY OF SCIENTIFIC RESEARCH INNOVATION IN INDEPENDENT COLLEGE}

\section{A. Strengthen scientific research institutions, perfect scientific research management system, and implement assessment and incentive mechanism.}

With the development of China's socioeconomic, the requirements will gradually increase. Independent colleges as the educational institutions services for the development of local social economy, it should also conform to the needs of the community to strengthen the construction of scientific research institutions, therewith formulate the scientific research management system in line with the management characteristics, and improve the requirements of developers, the implementation work of the results of personnel assessment and incentive mechanism, etc..

\section{B. Carry out interdisciplinary collaborative innovation, establish teacher development center, form the scientific research collaboration team.}

After launched collaborative innovation to implement the "innovation strong school", interdisciplinary collaborative innovation cooperation also began to sprout. More and more independent colleges are scrambling to implement collaborative innovation system mechanism, and establish a similar research center, institute and other research institutions. Students to carry out scientific research activities require the school departments to work together, if any link goes out of order will result in an obstacle of outstanding achievements in science and technology competition. Scientific research is an important way to improve the basic quality and academic level of teachers, and the fundamental purpose of teachers engaged in scientific research is to improve their own quality and teaching level, also encourage and support teachers to actively carry out scientific research activities. Although the independent college is mainly teaching work and lack of scientific research conditions, it can play the advantages in practical teaching. By participating in scientific research activities, teachers can constantly improve their knowledge structure, broaden their academic horizons, follow the frontiers of disciplines, and hold higher subject knowledge systems to make teaching more advanced and scientific. The development of teachers represents the strength of colleges to enhance, so it is necessary to build teacher development center, and the formation of scientific research cooperation team, to add new energy to the school. 


\section{To speed up the transformation of scientific research into opportunity and the establishment of local schools, enterprises, government tripartite cooperation.}

Collaboration team is mainly composed of schools, research institutes, enterprises, government and nongovernmental organizations and other organizations that cooperate with each other, and a research team with a solid strength and rich resources is formed by the collection of resources that solve a common problem. At present, there is a big difference in the level of scientific research in independent colleges, and the conversion rate of scientific research achievement is low. Therefore, it is necessary to speed up the implementation of the transformation of scientific research results, and through this opportunity to establish cooperation by local schools, enterprises, and government, also promote the development of cooperation.

\section{Pay attention to the construction of professional} laboratory and integrated application laboratory, cultivate a group of high-tech and high-skilled laboratory team.

At present, independent colleges are generally employed practitioner with practical experience; as well the retired teachers use the "old with new" way to set up a team. Lead to the situation of independent college teams that old teachers cannot do scientific research; external staffs have a strong utilitarian heart, and compare with each other. With the "scientific research strong school" becoming more obvious in the state of independent college, we should pay more attention to the construction of professional laboratory and comprehensive application oriented laboratory. Mainly to promote the development of science and technology applications, cultivate a group of high-tech and high-skilled laboratory team, and activate the independent college's own blood, to achieve the goal of science research enhancing colleges.

\section{E. "Research and development chain, industrial chain,} service chain" as dominant, build a regional platform for scientific research and innovation, and serve the local community.

The history of the development of higher education indicates that the development of education cannot be separated from the service of economic and social development; the development of independent college education is also the same. Cite a relatively well-known foreign idea, Wisconsin-idea, that is, "services for economic and social development". The development of colleges and universities is inseparable from the local economic and social development. With the success of "Wisconsin-idea" and the driven of "collaborative innovation strong school" situation, independent colleges follow three points to run through the economic and social development of the ecological chain, which are the positioning of local colleges, application oriented personnel training objectives and cultivation of school characteristics, and to develop economic and social service path. The path respectively conform to industry demand, promote the cultivation of talents; strengthen the practical application of technical training, the development of science and technology services; policy advantages, carry out policy advisory services; to promote college resources, promote the information service; using the dissemination of culture, the development of cultural communication service. In order to cultivate the social needs of highly skilled personnel, to serve the local community.

\section{F. Vigorously carry out the innovation and entrepreneurship training programs for college students, building experimental areas with special talents.}

Cultivate students with a certain academic level, the combination of professional education and entrepreneurship education. In order to promote the further development of the theory and practice of independent college education, the college students' innovation and entrepreneurship training program combines three kinds of projects, namely, technological innovation training, entrepreneurship training and entrepreneurship practice, to further strengthen the importance of practical teaching in the training of talents, creating a learning environment conducive to cultivating students' innovative thinking ability and improving their innovative and practical ability. Promote academic innovation, raise the level of academic research in independent colleges, vigorously carry out the students' innovation and entrepreneurship training program, and take this opportunity to build experimental zones of characteristic talents, formulate appropriate institutional mechanisms to ensure the efficiency of personnel training. Published quality academic papers that base on innovative and entrepreneurial projects, therefore develop a group of top-notch students with a certain academic level.

\section{CONCLUSION}

Scientific research ability is the core of the ability structure, scientific research of independent college still in the initial stage, teachers, especially young teachers' scientific research ability is very limited. Independent colleges strengthen teaching research and scientific research funding and the level construction and other ways to enhance scientific research capabilities, so as to further improve the teaching ability. The independent colleges combine teaching with scientific research to form a good interaction, improve students' project and scientific research level, and strive for more vertical project, based on regional, to strengthen the construction of horizontal projects, to increase the ability of scientific research and social services, establish the industry-university-research cooperation mechanism of the school system, form their own development characteristics, and enhance the school's social competitiveness.

\section{REFERENCES}

[1] The Central People's Government of the People's Republic of China, National Medium-Long-Term Educational Reform and Development Plan (2010-2020), July 2010.

[2] The Central People's Government of the People's Republic of China, National Long-Term Talent Development Plan (2010-2020), June 2010.

[3] China Education News Network, General Secretary Hu Jintao speech at the celebration of the 100 anniversary of Tsinghua University's conference, October 2015. 
[4] Feng, W., Yao, K., Sun, E., \& University, N., Study and practice on talents' training mode through cooperation of university-industry for independent colleges. Experimental Technology \& Management, vol. 30, pp. 21-23, October 2013.

[5] Yin, J., Zhang, J., Qiao, L., Xin, P. U., \& Cui, Y. Q., Research on innovation ability cultivation of the independent colleges. Research \& Exploration in Laboratory, vol. 35, pp. 190-193, July 2016.

[6] Wang J., Wu R., Innovative Strategy of the Managing Mode for Research Staff in Independent Colleges, Journal of National Academy of Education Administration, pp. 40-43, August 2015. 